\title{
Komunikasi Interprofesional Dalam Peningkatan Keselamatan Pasien: Systematic Review
}

\author{
Hirza Ainin Nur ${ }^{1}$, Agus Santoso² \\ 1,2 Fakultas Kedokteran, Universitas Diponegoro, Semarang
}

\section{Informasi Artikel}

\author{
Riwayat Artikel: \\ Diterima 29 Desember 2017 \\ Kata Kunci: \\ Komunikasi; \\ Interprofesional; Kolaborasi; \\ Keselamatan Pasien
}

\section{PENDAHULUAN}

Kompleksitas masalah kesehatan yang ada di Indonesia yang diimbangi dengan tingginya pemahaman masyarakat akan pelayanan kesehatan membuat rumah sakit berlomba-lomba untuk meningkatkan kualitas pelayanannya. Kualitas suatu rumah sakit sebagai institusi yang menghasilkan produk teknologi jasa kesehatan sangat bergantung pada kualitas pelayanan medis dan pelayanan keperawatan yang diberikan kepada pasien (Tjiptono,2008). Salah satu sarana yang dapat menunjang kualitas pelayanan kesehatan yaitu dengan komunikasi interprofesional yang efektif. Dengan adanya komunikasi dan kolaborasi antar tim tenaga kesehatan, pelayanan perawatan pasien akan lebih terjamin sehingga pasien merasa puas dan kualitas pelayanan kesehatan pun dapat meningkat.

Komunikasi merupakan salah satu elemen yang paling penting dalam kolaborasi interprofesional (Suter et al, 2009). Komunikasi yaitu proses penyampaian pesan/berita dari seseorang ke orang lain sehingga kedua belah pihak terjadi adanya saling pengertian. (Ernawati, 2009). Komunikasi diperlukan dalam pelayanan kesehatan. Hal ini dikarenakan komunikasi kesehatan merupakan komponen yang fundamental dalam perawatan pasien (Riesenberg, 2010). Komunikasi bagian dari human communication dimana proses komunikasi 
kesehatan ini merupakan transaksi antar tim kesehatan dengan klien maupun keluarga klien (Mundakir, 2006).

Ketidakakuratan informasi dapat menimbulkan dampak yang serius pada pasien, hampir 70\% kejadian sentinel yaitu kejadian yang mengakibatkan kematian atau cedera yang serius di rumah sakit disebabkan karena buruknya komunikasi. Pernyataan di atas sejalan dengan pernyataan Angood (2007) yang mengungkapkan bahwa berdasarkan hasil kajian data terhadap adanya adverse event, near miss dan sentinel event di rumah sakit, masalah yang menjadi penyebab utama adalah komunikasi. Komunikasi interprofesi merupakan faktor yang sangat berpengaruh dalam meningkatkan keselamatan pasien, karena melalui komunikasi interprofesi yang berjalan efektif, akan menghindarkan tim tenaga kesehatan dari kesalahpahaman yang dapat menyebabkan medical error (Berridge, 2010).

$$
\text { Data laporan dari Insiden }
$$

Keselamatan Pasien Nasional (IKPN) menyebutkan bahwa pada tahun 2008 dan 2009 jenis KNC ada 103 (70\%) dan KTD 43 (30\%). Akibat insiden tersebut sebanyak $6 \%$ menimbulkan kematian, $1 \%$ cedera irreversible, $7 \%$ cedera reversible, $16 \%$ cedera ringan, $70 \%$ tidak cedera. Permasalahan yang paling utama dan dominan dari insiden keselamatan pasien adalah komunikasi.

Data di salah satu rumah sakit swata di Jawa Tengah menunjukkan bahwa pada tahun 2009 ditemukian 11 kasus yang terdiri dari 48\% insiden KTD dan 52\% KNC. Di tahun 2010 ditemukan 23 kasus dimana sebanyak 39\% KTD dan 61\% KNC. Kejadian yang menyebabkan kematian belum ditemukan. Dari data tersebut permasalahan yang paling banyak terjadi yaitu komunikasi antar petugas kesehatan yang tidak terintegrasi dengan baik.

Akibat dari banyaknya kejadian tersebut komunikasi efektif dimasukkan dalam sasaran keselamatan pasien (JCI, 2011). Komunikasi efektif merupakan komunikasi yang tepat waktu, akurat, lengkap, jelas, dan dipahami oleh penerima sehingga dapat mengurangi kesalahan dan meningkatkan keselamatan pasien. Maka dalam komunikasi efektif harus dibangun aspek kejelasan, ketepatan, sesuai dengan konteks baik bahasa dan informasi, alur yang sistematis, dan budaya (KARS, 2012).

Faktor-faktor yang mempengaruhi kurang efektifnya komunikasi meliputi tenaga kesehatan yang kurang kompeten, kurangnya ketrampilan dan pelatihan tentang keselamatan pasien, kurangnya koordinasi dan kinerja tim tenaga kesehatan. Oleh karena itu dibutuhkan suatu metode pengembangan komunikasi interprofesional yang efektif yang erat kaitannya dalam pelayanan kesehatan.

Berdasarkan fenomena di atas maka disusun literature review tentang inovasi dan pengembangan komunikasi interprofesional yang efektif pada pelayanan kesehatan. Untuk mengetahui efektivitas komunikasi interprofesional dalam peningkatan keselamatan pasien.

\section{METODE}

Metode yang digunakan yaitu systematic review, dimana artikel penelitian dicari dengan beberapa cara pencarian dan kata kunci, sehingga mendapatkan artikel yang sesuai dengan kriteria inklusi dan eksklusi kemudian dilakukan review dari semua artikel tersebut. Kriteria inklusi dari artikel yang dicari yaitu: Artikel terkait bentuk pengembangan komunikasi interprofesional, Tahun penelitian 20112016, Artikel berbahasa Inggris, Artikel dengan pdf full text. Kriteria eklusi dari artikel yang dicari yaitu: Selain artikel penelitian tahun 2011-2016; Artikel yang tidak menggunakan bahasa Inggris; Artikel yang ditampilkan tidak full text

\section{STRATEGI PENCARIAN LITERATUR}

Peneliti melakukan strategi pencarian literatur dengan menggunakan sistem pencari Ebsco, PubMed, dan Google Scholar dengan strategi eliminasi literature sesuai dengan kriteria inklusi dan ekslusi. 
Tabel 1.Strategi Pencarian Literature

\begin{tabular}{lll}
\hline $\begin{array}{l}\text { Database } \\
\text { tahun } \\
\mathbf{2 0 1 1 -}\end{array}$ & Search & Number \\
$\mathbf{2 0 1 6}$ & & \\
\hline Ebsco & $\begin{array}{l}\text { Interprofesional } \\
\text { Collaboration AND Patient }\end{array}$ & 278 \\
& $\begin{array}{l}\text { Safety } \\
\text { Interprofesional }\end{array}$ & 58 \\
PubMed & $\begin{array}{l}\text { Collaboration AND Patient } \\
\text { Safety }\end{array}$ & \\
$\begin{array}{l}\text { Google } \\
\text { Scholar }\end{array}$ & $\begin{array}{l}\text { Interprofesional } \\
\text { collaboration for improved } \\
\text { patient safety }\end{array}$ & \\
$\begin{array}{l}\text { Total } \\
\text { Judul }\end{array}$ & & 16.200 \\
$\begin{array}{l}\text { Seleksi } \\
\text { pertama } \\
\text { Seleski } \\
\text { kedua }\end{array}$ & & 16.536 \\
$\begin{array}{l}\text { Seleksi } \\
\text { terakhir } \\
\text { setelah } \\
\text { dilakukan } \\
\text { criteria } \\
\text { inklusi } \\
\text { dan } \\
\text { eksklusi }\end{array}$ & & 48 \\
\hline
\end{tabular}

\section{EKSTRAKSI DATA DAN METODE PENGKAJIAN KUALITAS STUDI}

Artikel atau jurnal yang sesuai dengan kriteria inklusi dilakukan pengkajian kualitas studi (critical appraisal) menggunakan Critical Appraisal Skills Program tools (CASP tools) dan kemudian dilakukan ekstraksi data untuk mengelompokkan data-data penting pada artikel jurnal. Penentuan kualitas jurnal dengan menggunakan prosentase hasil ekstraksi yaitu jurnal dikatakan mempunyai kualitas baik jika prosentase $80 \%-100 \%$, cukup 65\%-79\%, dan tidak baik 64\%.

ANALISIS DATA
Analisis data dilakukan dengan
mengelompokkan data-data hasil ekstraksi
berdasarkan tujuan, metodologi, dan hasil
(tabel 2) yang sesuai dengan hasil yang
akan diukur. Data yang sudah dikumpulkan
kemudian dicari persamaan dan
perbedaannya kemudian dilakukan
pembahasan.

Tabel 2. Analisis Data

\begin{tabular}{|c|c|c|c|c|c|c|}
\hline No & Penulis (tahun) & Judul & Jurnal & Tujuan & $\begin{array}{c}\text { Metodolog } \\
\text { i } \\
\end{array}$ & Hasil \\
\hline 1. & $\begin{array}{l}\text { Margo Paterson, } \\
\text { Jennifer Medves, } \\
\text { Nancy Dalgarno, } \\
\text { Anne O'Riordan, } \\
\text { Robyn Grigg } \\
\text { (2013) }\end{array}$ & $\begin{array}{l}\text { The Timely } \\
\text { Open } \\
\text { Communicatio } \\
n \text { for Patient } \\
\text { Safety Project }\end{array}$ & $\begin{array}{l}\text { Journal of } \\
\text { Research in } \\
\text { Interprofessio } \\
\text { nal } \\
\text { Practice and } \\
\text { Education } \\
2013 ; 3.1\end{array}$ & $\begin{array}{l}\text { Menciptakan } \\
\text { budaya } \\
\text { keselamatan } \\
\text { pasien melalui } \\
\text { komunikasi } \\
\text { interprofesional }\end{array}$ & $\begin{array}{l}\text { Mix } \\
\text { methods } \\
\text { dengan } \\
\text { design pre } \\
\text { dan post } \\
\text { survey, dan } \\
\text { focus group }\end{array}$ & $\begin{array}{l}\text { Adanya } \\
\text { peningkatan } \\
\text { komunikasi } \\
\text { interprofesional } \\
\text { untuk } \\
\text { meningkatkan } \\
\text { keselamatan } \\
\text { pasien }\end{array}$ \\
\hline 2. & $\begin{array}{l}\text { Debra Parker } \\
\text { Oliver, George } \\
\text { Demiris, Elaine } \\
\text { Wittenberg-Lyles, } \\
\text { Ashley Gage, } \\
\text { Mariah L, Jamie } \\
\text { Luetkemeyer } \\
\text { (2013) }\end{array}$ & $\begin{array}{l}\text { Patient Safety } \\
\text { Incidents in } \\
\text { Hospice Care: } \\
\text { Observations } \\
\text { from } \\
\text { Interdisciplina } \\
\text { ry Case } \\
\text { Conferences }\end{array}$ & $\begin{array}{l}\text { Journal of } \\
\text { Palliative } \\
\text { Medicine } \\
2013 ; 16 ; 12 .\end{array}$ & $\begin{array}{l}\text { 1. Mengeksplor } \\
\text { jenis insiden } \\
\text { keselamatan } \\
\text { pasien yang } \\
\text { terjadi pada } \\
\text { perawataan } \\
\text { rumah } \\
\text { 2. Mengeksplor } \\
\text { banyaknya } \\
\text { insiden ini } \\
\text { diakui oleh staf } \\
\text { rumah sakit } \\
\text { dan / atau } \\
\text { pasien atau } \\
\text { pengasuh } \\
\text { sebagai insiden } \\
\text { keselamatan } \\
\text { pasien }\end{array}$ & $\begin{array}{l}\text { Qualitative } \\
\text { dengan } \\
\text { randomized } \\
\text { clinical trial }\end{array}$ & $\begin{array}{l}\text { Case conference } \\
\text { efektif untuk } \\
\text { menurunkan } \\
\text { insiden } \\
\text { keselamatan } \\
\text { pasien pada } \\
\text { perawatan } \\
\text { rumah }\end{array}$ \\
\hline
\end{tabular}




\begin{tabular}{|c|c|c|c|c|c|c|}
\hline No & Penulis (tahun) & Judul & Jurnal & Tujuan & $\begin{array}{c}\text { Metodolog } \\
\text { i } \\
\end{array}$ & Hasil \\
\hline 3. & $\begin{array}{l}\text { Gwendolyn } \\
\text { Lancaster, } \\
\text { Stephanie } \\
\text { Kolakowsky- } \\
\text { Hayner, Joann } \\
\text { Kovacich, Nancy } \\
\text { Greer-Williams } \\
\text { (2015) }\end{array}$ & $\begin{array}{l}\text { Interdisciplina } \\
\text { ry } \\
\text { Communicatio } \\
n \text { and } \\
\text { Collaboration } \\
\text { Among } \\
\text { Physicians, } \\
\text { Nurses, and } \\
\text { Unlicensed } \\
\text { Assistive } \\
\text { Personnel }\end{array}$ & $\begin{array}{l}\text { Journal of } \\
\text { Nursing } \\
\text { Scholarship } \\
2015 ; 47-3 ; \\
275-294\end{array}$ & $\begin{array}{l}\text { Mengeksplorasi } \\
\text { potensi koordinasi } \\
\text { perawatan } \\
\text { interdisiplin } \\
\text { berbasis rumah } \\
\text { sakit oleh dokter, } \\
\text { perawat, dan } \\
\text { unlicensed assistive } \\
\text { personnel (UAPs). }\end{array}$ & $\begin{array}{l}\text { Qualitative } \\
\text { dengan } \\
\text { design } \\
\text { fenomenolo } \\
\text { gi }\end{array}$ & $\begin{array}{l}\text { Koordinasi } \\
\text { antara dokter, } \\
\text { perawat, dan } \\
\text { unlicensed } \\
\text { assistive } \\
\text { personnel } \\
\text { (UAPs) dapat } \\
\text { meningkatkan } \\
\text { komunikasi, } \\
\text { kolaborasi, dan } \\
\text { keselamatan } \\
\text { pasien }\end{array}$ \\
\hline 4. & $\begin{array}{l}\text { Christian Gausvik, } \\
\text { Ashley Lautar, } \\
\text { Lisa Miller, } \\
\text { Harini Pallerla, } \\
\text { Jeffrey } \\
\text { Schlaudecker } \\
\text { (2015) }\end{array}$ & $\begin{array}{l}\text { Structured } \\
\text { nursing } \\
\text { communicatio } \\
\text { n on } \\
\text { interdisciplina } \\
\text { ry acute care } \\
\text { teams } \\
\text { improves } \\
\text { perceptions of } \\
\text { safety, } \\
\text { efficiency, } \\
\text { understanding } \\
\text { of care plan } \\
\text { and teamwork } \\
\text { as well as job } \\
\text { satisfaction }\end{array}$ & $\begin{array}{l}\text { Journal of } \\
\text { Multidiscipli } \\
\text { nary } \\
\text { Healthcare } \\
2015 ; 8 ; 33- \\
37\end{array}$ & $\begin{array}{l}\text { Mengembangkan } \\
\text { cara-cara untuk } \\
\text { meningkatkan } \\
\text { komunikasi } \\
\text { interdisiplin guna } \\
\text { meningkatkan } \\
\text { kualitas pelayanan } \\
\text { dan keselamatan } \\
\text { pasien }\end{array}$ & $\begin{array}{l}\text { Mix } \\
\text { methods } \\
\text { dengan } \\
\text { design } \\
\text { control } \\
\text { group } \\
\text { kelompok } \\
\text { inetrvensi } \\
\text { menggunak } \\
\text { an metode } \\
\text { SIBR } \\
\text { (Structured } \\
\text { Interdisiplin } \\
\text { ary Bedside } \\
\text { Rounds), } \\
\text { sedangkan } \\
\text { kelompok } \\
\text { control } \\
\text { menggunak } \\
\text { an ronde } \\
\text { tradisional } \\
\text { (physician- } \\
\text { centric } \\
\text { rounding) }\end{array}$ & $\begin{array}{l}\text { Metode SIBR } \\
\text { lebih efektif } \\
\text { untuk } \\
\text { meningkatkan } \\
\text { komunikasi dan } \\
\text { kolaborasi } \\
\text { interprofesi } \\
\text { serta kepuasan } \\
\text { kerja terhadap } \\
\text { keselamatan } \\
\text { pasien } \\
\text { dibanding } \\
\text { dengan ronde } \\
\text { tradisional }\end{array}$ \\
\hline
\end{tabular}

\section{HASIL}

Dari keempat jurnal yang digunakan mempunyai kualitas artike yang baik dengan hasil menunjukkan bahwa komunikasi interprofesional dapat meningkatkan keselamatan pasien sehingga insiden keselamatan pasien dapat berkurang. Adapun hasilnya adalah sebagai berikut :

Jurnal pertama yang berjudul The Timely Open Communication for Patient Safety Project oleh Paterson et al (2013) menunjukkan hasil bahwa komunikasi dan kolaborasi tim sangat efektif untuk meningkatkan keselamatan pasien. Studi kuantitatif pada jurnal ini untuk mengetahui gambaran responden tentang praktik kolaborasi dan keselamatan pasien. Sedangkan studi kualitatif menggunakan studi kasus yang bertujuan untuk mengetahui efek intervensi pendidikan terhadap komunikasi dan keselamatan pasien. Pada jurnal ini dilakukan 5 tahap intervensi yaitu (1) survey pra intervensi untuk mengetahui gambaran persepsi responden dengan CPAT (Collaborative Practice Assessment Tool) \& PHSYCO (Patient Safety Culture in Healthcare Organizations), (2) intervensi kelompok terarah kepada responden secara tatap muka, (3) Intervensi dengan menggunakan modul pembelajaran online untuk setiap responden, (4) intervensi dengan aktivitas 
tatap muka untuk pengembangan dan implementasi bahan orientasi pasien, (5) survey Post intervensi dan FGD. Dimana hasilnya menunjukkan bahwa komunikasi dan kolaborasi tim sangat efektif untuk meningkatkan keselamatan pasien. Hasil dari pre dan post survey memiliki nilai ratarata 0,5 lebih besar sehingga dapat dikatakan hasilnya signifikan.

Penelitian yang dilakukan oleh Oliver et al (2013) pada jurnal kedua dengan judul Patient Safety Incidents In Hospice Care: Observations From Interdisciplinary Case Conferences. Data dikumpulkan menggunakan study kualitatif dengan design randomized clinical trial. Studi kualitatif yaitu melalui wawancara dan diskusi dengan tim interdisiplin case conferences. Randomized clinical trial melalui video recorder yang dipaparkan pada dua kelompok intervensi, dimana 1 kelompok staf hospice dengan partisipasi caregiver dan 1 kelompok staf hospice tanpa partisipasi cargiver. Penelitian dilakukan selama 6 bulan yang menyatakan hasil bahwa sebagian besar $(92,6 \%)$ caregiver atau staf hospice dapat mengidentifikasi adanya masalah keselamatan pasien, dan mereka mengakui bahwa selama ini terdapat insiden keselamatan pasien. Sehingga caregiver dan staf hospice dapat melakukan pencegahan terkait keselamatan pasien. Hasil ini menunjukkan bahwa metode case conferences yang telah dilakukan dapat menurunkan insiden keselamatan pasien.

Jurnal ketiga yang diteliti oleh Lancaster et al (2015) tentang Interdisciplinary Communication And Collaboration Among Physicians, Nurses, And Unlicensed Assistive Personnel. Penelitian ini menggunakan studi kualitatif dengandesign fenomenologi melalui wawancara semi terstruktur secara face to face terkait 10 pertanyaan tentang Understanding Interdisciplinary Communication Among Physicians, Nurses, and Unlicensed Assistive Personnel dengan partisipan 12 dokter, 13 perawat, dan 11 UAPs. Dimana hasilnya yaitu dengan adanya kerjasama dan koordinasi antara dokter, perawatm dan
UAPs dapat meningkatkan komunikasi, kolaborasi dan juga meningkatkan keselamatan pasien.

Jurnal keempat dengan judul Structured Nursing Communication On Interdisciplinary Acute Care Teams Improves Perceptions of Safety, Efficiency, Understanding of Care Plan And Teamwork As Well As Job Satisfaction oleh Gausvik et al (2015). Metode yang digunakakan adalah mix methods studi comparasi dengan one group test, dimana kelompok intervensi sebanyak 24 staf menggunakan metode SIBR (Structured Interdisiplinary Bedside Rounds) dalam melakukan perawatan pada pasien, sedangakan untuk kelompok control sebanyak 38 staf menggunakan metode ronde tradisional (physician-centric rounding). Penelitian ini menunjukkan hasil bahwa kelompok intervensi yag menggunakan metode SIBR 100\% lebih efektif untuk meningkatkan komunikasi dan kolaborasi interprofesi serta kepuasan kerja terhadap keselamatan pasien dibanding dengan kelompok control yang hasilnya $76 \%$.

\section{DISKUSI}

Dari pemaparan empat jurnal terdapat kesamaan dan perbedaan. Kesamaannya yaitu sama-sama menggunakan komunikasi interprofesional untuk meningkatkan keselamatan pasien. Perbedaannya yaitu jenis atau metode komunikasi interprofesional yang digunakan berbeda.

Pada jurnal pertama dengan judul The Timely Open Communication for Patient Safety Project menggunakan pelatihan komunikasi TOC (Timely Open Communication) untuk meningkatkan keselamatan pasien. Pada jurnal kedua Patient Safety Incidents In Hospice Care : Observations From Interdisciplinary Case Conferences menggunakan metode case conference untuk menurunkan insiden keselamatan pasien. Jurnal ketiga Interdisciplinary Communication And Collaboration Among Physicians, Nurses, And Unlicensed Assistive Personnel dengan wawancara semi terstruktur terkait 
kerjasama dan koordinasi dari dokter, perawat, dan unlicensed assistive personnel (UAPs). Jurnal keempat Structured Nursing Communication On Interdisciplinary Acute Care Teams Improves Perceptions of Safety, Efficiency, Understanding of Care Plan And Teamwork As Well As Job Satisfaction membandingkan keefektivan metode SIBR (Structured Interdisiplinary Bedside Rounds) dengan ronde tradisional (physician-centric rounding). Dari keempat jurnal diatas komunikasi interprofesional yang dipakai sama-sama dapat meningkatkan keselamatan pasien.

Komunikasi adalah proses interpersonal yang melibatkan perubahan verbal dan nonverbal dari informasi dan ide. Sedangkan komunikasi interprofesi pelayanan kesehatan yaitu komunikasi yang dilakukan oleh tenaga kesehatan (dokter, perawat, apoteker, ahli gizi, fisioterpis, dll) yang saling bekerjasama guna perawatan dan kesembuhan pasien (Potter \& Perry, 2009). Komunikasi Interprofesi sangat diperlukan dalam memberikan pelayanan kesehatan pasien. Komunikasi dikatakan efektif apabila dilandasi keterbukaan, kejujuran dan pengertian akan kebutuhan, harapan, maupun kepentingan (Yusa, 2006). Komunikasi yang terbuka antar petugas kesehatan sangat berdampak positif bagi perawatan pasien. Komunikasi yang efektif dan kerjasama tim penting dalam rangka peningkatan kualitas pelayanan dan perawatan pasien yang aman termasuk komunikasi dalam berkolaborasi antara perawat-dokter. Sebaliknya kegagalan dalam komunikasi akan menyebabkan ketidakpuasan yang bisa mengancam keselamatan pasien (Leonard, 2004).

Keselamatan pasien menjadi tuntutan masyarakat baik di dalam maupun luar negeri. Pelaksanaan program keselamatan pasien dirumah sakit yang perlu dilakukan terkait sasaran keselamatan pasien tersebut meliputi ketepatan identifikasi pasien, peningkatan komunikasi yang efektif, peningkatan keamanan obat yang perlu diwaspadai, kepastian tepat-lokasi, tepatprosedur, pengurangan risiko infeksi terkait pelayanan kesehatan, dan pengurangan risiko pasien jatuh. Dari enam sasaran keselamatan pasien, unsur yang utama dari layanan asuhan ke pasien adalah komunikasi efektif (Permenkes RI No. 1691/Menkes/Per/VIII/2011). Komunikasi yang efektif merupakan kunci bagi perawat untuk mencapai keselamatan pasien berdasarkan sasaran keselamatan pasien di rumah sakit.

Dengan adanya akreditas KARS 2012 dan JCI rumah sakit mengembangkan komunikasi interprofesi yang ada baik menggunakan komunikasi SBAR, case conference, ronde keperawatan, dan rapat tim pelayanan kesehatan. Karena komunikasi yang efektif masuk di dalam sasaran keselamatan pasien dan merupakan penilaian dari akreditasi rumah sakit. Karena kesalahan dalam komunikasi merupakan penyebab terbesar terjadinya adverse event.

\section{KESIMPULAN}

Komunikasi interprofesi sangat penting dilakukan guna meningkatkan keselamatan pasien dan menurunkan angka insiden keselamatan pasien. Pada systematic review ini disimpulkan bahwa komunikasi interprofesi efektif untuk meningkatkan keselamatan pasien di rumah sakit. Diharapkan rumah sakit di Indonesia menerakan komunikasi interprofesi seperti ronde keperawatan, case conference, rapat tim, dll. Disamping dapat meningkatkan keselamatan pasien penerapan komunikasi interprofesi juga dapat meningkatkan mutu pelayanan kesehatan dan profesionalisme kerja.

\section{DAFTAR PUSTAKA}

Angood. (2007). Patient Safety Archeiving New Standard for Care.

Ernawati. (2009). Buku Saku Komunikasi Keperawatan Aplikasi dalam Pelayanan. Yogyakarta: Graha Ilmu.

Gausvik et al. (2015). Structured Nursing Communication On Interdisciplinary Acute 
Care Teams Improves Perceptions Of Safety, Efficiency, Understanding Of Care Plan And Teamwork As Well As Job Satisfaction. Journal of Multidisciplinary Healthcare; 8; 33-37.

Joint Commission International (2011). Standar Akreditasi Rumah Sakit Enam Sasaran Keselamatan Pasien. Edisi ke-4.

Komisi Akreditasi Rumah Sakit. (2012). Intrument Akreditasi Rumah Sakit Versi 2012. Edisi 1. Jakarta.

Kongres XII PERSI. (2012). Seminar Keselamatan Pasien. Jakarta.

Lancaster et all. (2015). Interdisciplinary Communication And Collaboration Among Physicians, Nurses, And Unlicensed Assistive Personnel. Journal of Nursing Scholarship; 47; 3; 275-294.

Mundakhir. (2006). Komunikasi Keperawatan Aplikasi dalam Pelayanan. Yogyakarta: Graha Ilmu.

Oliver et al. (2013). Patient Safety Incidents In Hospice Care : Observations From Interdisciplinary Case Conferences. Journal of Palliative Medicine; 16; 12.

Paterson et al. (2013). The Timely Open Communication for Patient Safety Project. Journal of Research in Interprofesional Practice and Education; 3; 1.

Peraturan Menteri Kesehatan RI Nomor 1691/Menkes/Per/VIII/2011 tentang

Keselamatan Pasien di Rumah Sakit.

Potter, P. A \& Perry, A. G. (2005). Buku Ajar Fundamental Keperawatan: Konsep, Proses Dan Praktik. Edisi 4. (Y. Asih et al, penerjemah). Jakarta: EGC

Riesenberg, A, L., Leitzsch, J., \& Cunningham, M. 2010. Nursing Handoffs : A Systemic Review of The Literature : Surprisingly Little Is Known About What Constitutes Best Practice. American Journal Of Nursing.

Tjiptono, Fandy. (2008). Strategi Pemasaran, Edisi 3. Yogyakarta : ANDI. 